\title{
A Literature Review of Team-Member Exchange and Prospects
}

\author{
Zheng Chen \\ School of Business Administration, South China University of Technology, Guangzhou, China \\ Email: chenzheng_6@foxmail.com
}

How to cite this paper: Chen, Z. (2018) A Literature Review of Team-Member Exchange and Prospects. Journal of Service Science and Management, 11, 433-454. https://doi.org/10.4236/jssm.2018.114030

Received: July 13, 2018

Accepted: August 21, 2018

Published: August 24, 2018

Copyright (C) 2018 by author and Scientific Research Publishing Inc. This work is licensed under the Creative Commons Attribution International License (CC BY 4.0).

http://creativecommons.org/licenses/by/4.0/

\section{(c) (i) Open Access}

\begin{abstract}
Team-member exchange refers to individual's perception of the quality of working relationships as the whole within the team, which has been recognized by many scholars to the importance of team processes. However, the research of team-member exchange is still scarce. To advance team-member exchange of research, and gradually build and improve the development of team-member exchange theory paralleled with leader-member exchange theory, this paper reviews recent team-member exchange research in aspects of research origins, concept, measurement, theoretical perspectives, function modes and so on, and points out future directions in team-member exchange research.
\end{abstract}

\section{Keywords}

Team-Member Exchange, Social Exchange Theory, Reciprocal Theory, Role Theory

\section{Introduction}

With the accelerating pace of knowledge creation and increasing environmental uncertainty, innovation has become an inevitable choice for organizations to adapt to changes in the environment, maintain and strengthen their competitive advantage [1]. At the same time, the team has gradually become a widely used work design [2]. Especially when in dynamic and complex tasks, teams can quickly adapt to changing condition and promote the creation of knowledge and the creation of innovation results for its characteristics of work autonomy, decision-making flexibility, and rapid response [3]. In such context, exploring the factors that affect team-related output and its mechanisms has become a common concern in the theoretical and practical world. 
In a team, with role of leader relatively weak, the interaction between team members becomes a key factor in determining team performance [4]. Concept of TMX proposed by Seers (1989) can describe quality of reciprocal relationships among team members in work situations [5]. Thus, TMX has increasingly been valued by scholars. However, the current research on TMX has not yet formed a complete system, and it is still difficult to answer questions such as what TMX origins from, how they are affected, and when they are affected. In order to promote the research of TMX and call more attention on TMX, the paper will sort out relevant literatures on TMX research. The article is organized by review including origin concepts, structure and measurement of TMX. Also, the paper covers review of TMX on theoretical backgrounding, predictive factors, proximal factors, remote factors and moderating mechanisms. In the end, the paper offers some ideas as well as suggestions on TMX future study.

\section{The Origin and Conceptual Connotation of Research on TMX}

\subsection{Research Origin}

Before Seers (1989) proposed the concept of TMX, although, scholars pay more attention on the organization's vertical exchange relationship-Leadership-Member Exchange (LMX), although "team" as the basic task execution unit has been widely and popularly used. As Leadership-member exchange theory has shown, employees' remuneration, and promotion opportunities in large extent depend on their relationship with their leaders, especially when leaders master a large amount of resources in the organization [6]. Therefore, the LMX relationship exerts a significant impact on employee performance, job satisfaction, organizational citizenship behavior, organizational commitment, and turnover intention [7] [8]. However, with the emergence of Shared Leadership [9] and Self-managed teams [10] [11], impact of leadership may be relatively weakening. In other words, the interaction between team members has a more obvious effect on individual performance and team performance. That's why understanding the role of horizontal exchange relationship in the work team is particularly urgent and important [12]. In such context, Seers (1989) proposed the concept of TMX basing on role theory and social exchange theory. TMX refers to the reciprocal exchange process between team members, including a member who not only aids, ideas, willingness to respond, to others but also get a certain degree of information, help and recognition from other members [5].

Once the concept of TMX was proposed, it attracted attention from academic community. The main reason for that can be summarized into two points. Firstly, TMX can promote comprehensive understanding of the internal exchange relationship of the team. To be more specific, in the team, while LMX can only reflect the vertical exchange relationship between leaders and members, TMX as a horizontal exchange relationship variable within the team is able to play a supplement role to the LMX relationship, which can also contribute to understand- 
ing of TMX in academic area [13]. Secondly, "team" is highly concerned about in the practical and academic area. With team-based work design increasingly thought highly of, more and more scholars began to figure out influencing factors of team output such as team innovation, team performance, team effectiveness, and team creativity. As for practical area, they hope for get more theoretical as well as practical guidance from academia too.

\subsection{Concept, Connotation and Types}

Seers (1989) proposed the concept of TMX based on role theory and social exchange theory, which means the process of reciprocal exchange between team members, including a member offer help, ideas, feedback for others and the degree of obtaining information, help, and recognition from other members [5]. TMX reflects the individual's overall perception of the quality of the work relationship within the team [14]. Unlike the leadership-member exchange (LMX) theory, which focuses on the vertical relationship between leaders and members [15], TMXs reflect the overall, horizontal reciprocal relationship between a member and other colleagues. Therefore, it is more representative of the quality of relationships at the team level [16]. Seers (1989) argues that in a self-management team, team members attitude and engagement towards work are related to such reciprocal relationship between team members [5]. Specifically, the higher the quality of TMX, the stronger the reciprocity between the members will be [12]. That is, if everyone's pay will be recognized and rewarded by others from team, then they are more willing to make contributions to achieve team goals together. On the contrary, the lower the TMX, the less likely the member's efforts are to be respected and rewarded by others, and correspondingly less willing to make efforts to abstain team goals. So TMX reflects the spirit of mutual assistance and altruism between team members [17] and the spirit of "rewarding oneself" [18]. Especially in innovative self-management teams (such as R \& D teams), single member with limited knowledge as well as capabilities usually fail to finish tasks for uncertainty and complexity of the task itself [19]. Instead, team goals can be effectively realized through collective power can be effectively realized. Thus, the process of interaction, mutual assistance, and information sharing among team members plays a crucial role in the creation of innovation results.

However, only a qualitative study published by Tse and Das borough in 2008 involves types of TMX until now. Based on the definition proposed by Seers (1989), Tse and Dasborough (2008) used qualitative research methods to identify two types of TMXs: task-oriented exchange and relation-oriented exchange [20]. Task-oriented exchanges means for idea sharing, feedback, information, and knowledge sharing, relationship-oriented exchanges include help, care, support, similar values and standards, intimacy of relationship, private sharing, friendship, and encouragement [20]. They further propose that TMX in low Quality contains only a small number of mission-oriented exchanges, while TMX in high-quality includes both task-oriented exchanges and relation- 
ship-oriented exchanges [21]. Relationships of TMX in high-quality help build recognition, appreciation, encouragement, mutual respect, and trust among team members, while Relationships of TMX in low relationships result in lack of respect, trust, and team cooperation among team members [16].

\section{TMX Structure Dimensions and Measurements}

Since construct of TMX put forward by Seers (1989), few scholars have questioned its concept, structural dimensions and measurement. More scholars explore scale as well as impact mechanism based on definition from Seers. Seers (1989) identified three dimensions of TMX in his research including meeting, exchange, and cohesiveness.

\subsection{Meeting}

The meeting dimension of TMX means to effectiveness of team meetings. Team meetings are an important way for team members to share information, share ideas, make suggestions, and solve problems [5]. An effective meeting plan should clarify the purpose and goal of the meeting, indicate what views or suggestions are necessary, and play a guiding role in the meeting. The effectiveness of team meetings directly depends on the quality of the organization team. So, a meeting can be described as successful ones only after that it can motivate people to work hard, promote them to resolve conflicts through communication, encourage them to share opportunities, create crucial results, and leave with a sense of accomplishment.

\subsection{Exchange}

When put in TMX context, exchange is a two-way reciprocal behavior between a member and a team [14]. That is, members spontaneously voluntarily provide support as well as feedback for other team members and share ideas them. In return, the member also received information, assistance, and recognition from team members [5]. In other words, exchange is acts of team members learning from each other and freely communicating feelings, ideas and opinions [22].

\subsection{Cohesion}

Cohesion refers to a common sense of belonging, characterized by cooperation, group identity, commitment, and positive interdependence [23]. Tziner and Vardi (1982) proposed two forms of cohesion-sexual emotional cohesion with emotional satisfaction and goal-oriented tool cohesion [24]. Both kinds of cohesion are considered essential for efficient team work.

Seers (1989) believes that the above three dimensions together constitute the concept of TMX. He developed a measurement scale that contains 18 items, of which the exchange dimension has 10 items, and meeting and cohesion dimension each has 4 items [5]. However, Seers et al. (1995) argued in their future study that the exchange dimension is the most reliable predictor for measuring 
TMX concept [14]. Only this dimension is sufficient to explain the individual's overall perception of the quality of the team's working relationship. Therefore, in his study made by 1995, only 10 measurement items were used to measure TMX quality (see Table 1 for specific measurement items). Half of the 10 items examined the members' contribution to the team, the other half examined the members' support from the team. Apart from that, Seers et al. (1995) showed that the scale had good reliability and validity through doing pre-test as well as post-test. Later, the scale has been widely recognized and applied in TMX studies.

Although most of the research on TMX directly used Seers (1989) concept and his measurement scale, some scholars choose to modify and develop new scales basing on scale carried out by Seers (1995). For example, Chae et al. (2015) used scales that contain only three items adapted by Zhou and George (2001) from Seers's 10 item scales. The scale includes questions like "I often asd other for help", "Members on this team willingly suggest better work methods to others", "Other members on this team recognize my potential" [1]. Monica $\mathrm{Hu}$ et al. (2012) used the scale of the 3 items developed by Alper, Tjosvold and Law (1998), like "Team members encourage each other to improve their work performance", The high quality of the relationships in the team makes members enthusiastic about their work and the atmosphere keeps them focused on their work all day long", "The interaction among team member is good" [25].

\section{The Theoretical Basis of TMX}

Since Seers (1989) put forward the theoretical classification of TMX based on role theory and social exchange theory. Scholars have explored mechanism of TMX impact from different perspectives, such as social exchange theory [1] [25] [26] [27] [28] [29], reciprocity theory [1] [25], social interaction theory [30] [31], social identity theory [26] [28], Social Network Theory [23], social interdependence theory [32], cooperation and competition theory [27], fairness and social comparison theory [4] and so on. Among all of them, social exchange theory and reciprocity theory are the most widely used in TMX research.

\subsection{Social Exchange Theory}

Social exchange theory is a sociological theory that emerged in the United States in the 1960s and spread widely in the world. It advocates the study of social behavior theory from perspective of the relationship between input and output of economics [33]. This theory focuses on the attributes of interpersonal relationships and social interactions. It reconceptualizes interpersonal communication as a social exchange phenomenon, believing that seeking benefits and avoiding harm are the basic principles of human behavior. People tend to increase their benefits or satisfaction and reduce their costs or sacrifice during interactions, 
Table 1. Measurements of TMX (Seers et al. 1995).

\begin{tabular}{cl}
\hline Question & \multicolumn{1}{c}{ Items } \\
\hline 1 & $\begin{array}{l}\text { How often do you make suggestions about better work methods to other team } \\
\text { members? }\end{array}$ \\
2 & $\begin{array}{l}\text { Do other members of your team usually let you know when you do something that } \\
\text { makes their jobs easier (or harder)? }\end{array}$ \\
3 & $\begin{array}{l}\text { How often do you let other team members know when they have done something that } \\
\text { your jobs easier (or harder)? }\end{array}$ \\
4 & How well do other team members of you team recognize your potential? \\
5 & How well do other members of your team understand your problems and needs? \\
6 & $\begin{array}{l}\text { How flexible are you about switching job responsibilities to make things easier for } \\
\text { other team members? }\end{array}$ \\
8 & In busy situations, how often do other team members ask you to help out? \\
9 & In busy situations, how often do you volunteer your efforts to help other on your team? \\
10 & $\begin{array}{l}\text { How willing are other members of your team to help finish work that was assigned to } \\
\text { you? }\end{array}$
\end{tabular}

which indicates that interpersonal communication is driven from "self-interest" [33]. The theory of social exchange, characterized by long-term unspecified obligations, argues that people are willing to socialize with people around in both their personal life and work. People temps to exchange trust, help, and feedback with each other [34]. Thus, theory of social exchange refers to a lasting interaction model that contains mutual debt responsibilities and commitments expressed in response to other individual needs, stemming from the informal relationship which generates trust and sense of obligation [35]. Social exchange theory can well explain the dynamic process of resource exchange between two or more people [36]. The theory holds the points that the higher the quality of workplace exchanges perceived by people, the greater their willingness to act altruistically in these relationships.

\subsection{Theory of Reciprocity}

The theory of reciprocity originated from the social exchange theory [37]. Reciprocal norm, a potential core rule of social exchange relations, is widely used in the field of organizational research. Additionally, it is very crucial for research on employee incentives in organizations [21]. The reciprocity theory believes that people will try to respond in the same way to what others have done to them. For example, a member might participate in cooperation and do altruistic behaviors (such as positive reciprocal behaviors) as return to the support and help from others. Oppositely, they might respond by vengeance to the negative treatment they perceive [25]. At present, the types of reciprocity most widely acknowledged are generalized reciprocity, balanced reciprocity, and negative reciprocity [37]. Among them, generalized reciprocity refers to altruistic behavior, 
balanced reciprocity refers to equal returns in a timely manner and negative reciprocity refers to pursuing one's own interests by harming other people's interests without paying attention to give returns to others [15]. When it comes to organizational research, reciprocity, seen as a powerful incentive source, is one of the important factors that determine employees' behavior [38]. Reciprocity can promote a high degree of consistency in collective action and motivate extra-role of behavior that favors organizational performance [39]. Therefore, TMX is a social exchange behavior based on the principle of reciprocity.

\subsection{Role Theory}

The role theory is a social psychology theory about how people's attitudes and behaviors are influenced by their role in society and social role expectations. Being a branch developed from the theory of symbolic interaction, the role theory tries to explain and reveal the law of people's behavior according to their status or identity [40]. Role theory holds the points that position of a person in social relationships determines a person's social behavior, which also means that people's social roles are played in the impact of social context [41]. The role theory mainly includes roles cognition, role learning and role expectations [40]. Roles cognition means that when in social organization activities, various social roles always tempt to interact with each other [42]. In a team, a team member's understanding of self-behavior and status is based on his/her understanding of behavior and status from other team members. Role learning refers to the fact that every person might be assigned different rights as well as duties facing social organizational activities, indicating that one's social role is constantly changing [38]. That's why in the process of personal socialization, team members will continue to learn different social behaviors matched with various roles according to their cognition to their roles [42]. The so-called role expectation represents people temps to have a certain expectation of members from the organization because of his organizational positions [40]. In other words, role expectations imply that one gets expectations put forward by others in comply with one's status and exert his/her understanding of such kind of expectations. In the team, individuals might get role expectations from their superior and coworkers. If individuals respond positively to and meet with these expectations, superior and coworkers might not only recognize individuals' team membership, but also provide them with information, resources, feedback and assistance, which eventually help build high-quality TMX relationships.

\section{TMX Predictors}

TMX have been proven to improve team members' job performance, job satisfaction, and organizational commitment. Additionally, employees with high TMX have fewer tendencies to turnover [13]. Therefore, more studies begin to trace TMX's source, focusing on the topic of "how quality of TMX relationship is affected", and trying to reveal the antecedents of TMX from the perspective of 
predictors. As research results show, TMX predictors are mainly concentrated in three aspects: individual level, team level and situational factors.

\subsection{Individual Level}

\subsubsection{Emotional Intelligence}

Emotional intelligence refers to the ability of individuals to perceive and generate emotions, to think about and understand emotion-related knowledge, and to reflect on and manage the ability to control emotions [43]. People with high emotional intelligence have strong perception and understanding of other people's emotions. They can accurately infer people's current feelings [44]. In addition, people with high emotional intelligence generally have stronger emotional management capabilities. They are able to well control their own emotions, develop diverse social skills, personal skills, and work-related skills, and can correctly deal with setbacks and stress [45]. Therefore, they are more likely to maintain good interpersonal relationships with others, have higher job performance, and as result are more likely to have higher job satisfaction. With sensitive perception of people's emotional changes and needs as well as appropriately corresponding, they are more likely to develop high-quality TMX relationships with other team members.

\subsubsection{Workplace Friendship}

Workplace friendship is defined as a non-exclusive workplace relationship that includes mutual trust, commitment, reciprocity, common interests, and values [46]. Workplace friendships are able to provide individuals with information and support which advance them job tasks, ease work pressure, and improve work quality [47]. Numerous studies have shown that workplace friendship plays an important role on building a healthy, supportive and beneficial work environment [46] [47] [48] [49]. If individuals develop friendships with other members in their work that transcend their formal colleagues' relationships, they will more trust, help and support each other. What's more, they are more willing to share information and solve problems for each other, which effectively advance the development of high-quality TMX relationships.

\subsubsection{Organizational Justice}

Organizational justice refers to fairness of individual perceived organizational treatment and their behavioral responses to such perceptions [50]. There are three types of organizational justice: equity distribution, procedural equity, and interactive equity [51]. All employees hope when in organization they can be treated according to their ability, experience and contribution so as to reduce insecurity and injustice [52]. Employees' sense of organizational justice is good to improve quality of relationships between employees as well as their colleagues and their desire to maintain existing relationships. This in turn encourages them to maintain this social exchange relationship in a reciprocal way [53]. Existing research shows that employees' perceptions of organizational fairness and interactional justice are positively related to TMX [54]. 


\subsubsection{Team Orientation}

Team orientation refers to the individual's willingness to become a member of the team and stay in the team [27]. Mohammed and Angell (2004) believe that high-team-oriented members perform better in team work because the high-level team orientation of members can ease conflict within the team, which effectively facilitate teamwork [55]. Therefore, in the case of a high level of team orientation, communication between team members will be more frequent, which also means team members are more willing to share information, share resources, and provide help and feedback with others.

\subsubsection{Leader-Member Exchange}

Herdman et al. (2014) proposed that the exchange relationship between leadership and subordinates might lay the tone for the entire work team [4]. That is, quality of exchange relationship between a member and his/her leader directly affects the way he/her treat to other team members. The way of interaction [56], Sherony and Green (2002) found in their research that similar individuals are more likely to develop intimate relationships based on dynamic equilibrium theory [31]. For example, when a leader develops high quality at the same time as employee A and employee B, A and B might also develop high-quality colleagues exchange relationships [31]. In other words, if a leader builds a high/low quality LMX relationship with employees A and B, then employees A and B will develop high/low TMX relationship coordinating with LMX relationship [31], which means $\mathrm{x}$ change relationship between leaders and other members might exert directly influence on exchange relationship between team members [57]. Thus, LMX play a role in shaping TMX.

\subsection{Team Level}

\subsubsection{Team Characteristics}

Alge et al. (2003) divided the team into four types according to time as well as duration of team's establishment: future team, past team, long-term team, and temporary team [58]. The future team means those teams that long-term cooperation will be built within the future even though there was no cooperation experience in the past, such as newly formed project teams. The past team refers to teams that are close to dissolution and will no longer continue to cooperate with in the future, such as teams near the end of the project. Long-term teams is such teams that not only have past cooperation experience but also have future cooperation as well as collaboration with like research and develop teams. Temporary teams are teams that have no previous experience in cooperation and will not have sustainable cooperation in the future, such as teams that were temporarily formed to complete unexpected tasks [58]. Alge et al. (2003) further pointed out that only members in a long-term team tends to invest more time and energy in interpersonal relationships, because team members from long-term team are more willing to share information or ideas with each other, provide advice, feedback when team members need, and aid when partners are in trouble, which 
in other words means they are more likely to develop high-quality TMX relationships [58]. Moreover, team size may influence TMX relationship [59]. In a large-size team, due to limited time and energy of team members, members can only develop higher-quality TMX relationships with certain members while maintain lower-quality TMX relationships with others [60]. Conversely, when in a small-size team, with the same goal to finish the task, members must show team work and thus frequency of communication as well as interaction among members become higher [59], making members more opportunities to share, support, and assist each other. It is therefore more likely to develop high quality TMX relationships.

\subsubsection{Group Cohesion}

Group cohesion refers to the degree of intimacy between group members and their desire to be part of the group [61]. If a work team is highly united, the socialization of group members will occur [62]. Studies have shown that group cohesion increases the exchange of information as well as resources between members, and also improve the likelihood that team members will perform extra-role behaviors such as helping others [63], thereby improving the quality of TMX relationships.

\subsubsection{Leader-Member Exchange Differentiation (LMXD)}

Leadership-member exchange difference is a team-level concept. It refers to the difference of quality of exchanges between leader and members, including differences in types (social exchanges as well as economy exchanges) and differences in quantities (high/low level of quality of exchanges) [64]. Le Blanc et al. (2012) believe that the LMXD will affect the team process, aggravate the relationship conflict, and impede team cooperation as well as exchange based on the fairness theory [65]. When a team's leadership-member exchange difference (LMXD) is at a high level, individuals with low-quality LMX relationships may experience unfairness and dissatisfaction [57], and may even be jealous [66], which in turn reduces communication and interaction between members in high-quality LMX relationships [67], and ignores help from other members, resulting in low-quality TMX relationships among team members [30].

\subsection{Situational Factors}

\subsubsection{Leadership Style}

Studies have shown that service leadership not only affects the exchange relationship between leaders and followers, but also influences exchange relationships among team members through emotional processes [18]. Zou et al. (2015) believe that service leadership is good to create a caring as well as mutual aiding team atmosphere through strengthening team identification, team vision and team building. In this process, team members' self-concept transits from individualism to collectivism, which leads them to create a sense of responsibility and duty to provide support as well as assistance to other members [18]. In addition, 
service leadership may build the open, fair, impartial and honest interaction atmosphere with their followers, creating a problem-driven and sincere communication environment within the team [68], which will encourage mutual trust among team members and build high quality of TMX relationship.

\subsubsection{Task Characteristics}

Chae et al. (2015) pointed out that the team conducts highly complex and innovative tasks through high-density communication [1]. As a highly complex and innovative task often implies great uncertainty and difficulty [2] [69], team members have to exchange information as well as knowledge to each other frequently, supplemented by a great deal of interaction, cooperation and coordination, and communication can be completed. In other words, the higher the task complexity and innovation, the higher the quality of the TMX relationship of the team members.

\section{Near-End Impact of TMX}

\subsection{Individual Level}

\subsubsection{Knowledge Sharing}

Liu et al. (2011) believe that organizational atmosphere will affect individuals' willingness to share knowledge. High-quality TMX relationship not only helps create an atmosphere of mutual help and reciprocity, but also provide team members with more opportunities to share and communicate with each other, which effectively inspires individuals to share knowledge [70]. In addition, Monica Hu et al. (2012) argue that individuals in low-quality TMX relationships limit their exchange behavior to the needs of the task, while individuals with high-quality TMX relationships are more likely to participate in high-level knowledge-sharing behaviors or in resource exchange and help behavior beyond the task requirements [25].

\subsubsection{Team Commitment and Organizational Commitment}

Commitments are often defined as the relative strengths of individual identification and involvement in an organization [71]. TMX will give individuals a strong exchange ideology, a kind of reward belief that individuals generate through organizational support [70], which depends entirely on how the organization treats it, and ultimately embodied in the individual's attitudes and behaviors. Research shows that team members with a strong sense of exchange are more willing to make helpful behaviors that benefit the team and other members, and further develop as team commitment, organizational loyalty, and organizational commitment [72].

\subsubsection{Job Involvement and Work Engagement}

Job involvement refers to a dynamic, dedication and focus on a work-related positive mental state [73]. In other words, job involvement reflects the level of psychological employees input when performing certain tasks and work roles. High-quality TMX relationships can often create a safe, open, as well as positive 
interpersonal and psychological environment in which employees have tendency to exchange resources, feedback the work tasks and actively participate in their own work roles. Work engagement is a role-based concept of motivation, referring individuals play their role by investing in physical, emotional, and cognitive energy [74]. Empirical studies have shown that high-quality TMX relationships are associated with safe as well as positive interpersonal environment. In such environment, individuals tend to more proactively report work mistakes, more likely to feel comfortable while interacting with team members, and more involve in the work role [29].

\subsubsection{Helping Behavior}

TMX represents quality of exchange relationships between collaborators in the workforce [14], and extensive research has shown that team members with high-quality TMX relationships conduct a series of reciprocal actions with collaborators [12] [22] [75], especially for helper behavior [26], to show their emphasis on these social exchange relationships.

\subsubsection{Intrinsic Motivation}

Intrinsic motivation is mainly a kind of activity or working motivation triggered by the characteristics of activity process or individual's internal spiritual needs [76]. George et al. (2015) believe that task feedback from team members can help employees focus their attention on tasks and motivate them to believe that their team members will support them in finding new solutions to problems [2]. Therefore, by providing feedback, sharing ideas, and helping each other, high-quality TMX relationships can motivate employees to become interested in a given task and motivate them to be more creative. That is, high-quality TMX relationships can strengthen employees' creative behavior, Intrinsic motivation [29].

\subsubsection{Self-Efficacy}

Positive emotions and mental health. Related research found that TMX typical characteristics of TMX like reciprocity, mutual trust, as well as mutual help can enhance the positive emotions of team members [20], mental health [77], and self-efficacy [78].

\subsection{Team Level}

\subsubsection{Team Cohesion}

Team cohesion as a team-level concept mainly emerged from interaction between team members [23]. Tse and Dasborough (2008) classify TMX relationships into two dimensions: task-oriented exchange and relationship-oriented exchange. Low-quality TMX relationships contain only task-oriented exchanges, while high-quality TMX relationships contain both task-oriented exchanges and relationships-oriented exchange [20]. When a member has a high-quality TMX relationship, he will communicate more frequently with other team members, and they will not only exchange information and cooperate with the tasks re- 
quired to complete the task, but also communicate outside the work and even develop friendship. Therefore, members in a high-quality TMX relationship will have a sense of responsibility toward the team and team members with high frequency of communication, resulting in greater team cohesion.

\subsubsection{Team Cooperation}

Hoegl and Gemuenden (2001) identified six dimensions of teamwork through empirical research-communication, collaboration, balancing member contributions, mutual support, effort, and cohesion [69]. These six dimensions cover both task-related interactions and social interactions within the team. In order to achieve team goals under certain time and budget constraints, team members need to communicate relevant information openly [3], coordinate individual activities, and ensure that all team members fully contribute their knowledge and reach their potential [14]. Moreover, team members will support each other when in team discussions and in performing individual tasks [79], making work regulations established and maintained effectively and eventually develop appropriate levels of team cohesion [24]. As for those team members in a high-quality TMX relationship, they will be more proactive in sharing ideas as well as information, supporting other members' work, making constructive comments when they encounter problems, fully tapping the potential of others, affirming and recognizing the contribution from others in a timely manner and finally resulting in high quality teamwork.

\section{Far-End Influence of TMX}

\subsection{Individual Level}

Existing research on the far-end impact of TMX is mostly at the individual level. For example, through meta-analysis, Banks et al. (2014) found that individual-level TMXs can on the one hand improve team members' job performance, job satisfaction, and organizational commitment. On the other hand, individual-level TMX can reduce team members' willingness to turn over as well [13]. In addition, relevant research has also found that individual-level TMXexert positive influence on individuals' organizational citizenship behavior [26], innovative behavior [80], the willingness to share knowledge [25] [70] and the socialization process after entering the organization. It can also ease individuals' role of pressure [81], reduce relationship conflicts and suppress the impact of job burnout [82].

\subsection{Team Level}

At present, there are few studies on the far-end effects of TMX relationships at the team level. Only a few scholars have discussed the output of TMX at team level. For example, Chae et al. (2015) pointed out that the higher the quality of TMX, the greater the willingness to share with, help and offer feedback to other team members, making team innovation performance as well as team effectiveness improved [1]. Liu et al. (2011) find that TMX positively related to team 
knowledge sharing, team commitment, and team performance [70]. Tse et al. (2008) show that high-quality TMX relationships have a positive impact on team effectiveness and team efficacy [21].

\section{TMX Moderating Mechanism}

\subsection{The First Stage Moderation}

There is not much research on the regulatory mechanisms of TMX, and most of them focus on the first stage of regulation (Figure 1). Firstly, at the individual level, studies by Monica $\mathrm{Hu}$ et al. (2012) showed that trust positively regulates the relationship between knowledge sharing and TMX [25]. To be more specific, mutual trust will not only motivate individuals to share knowledge, but also help build good colleagues relationship through reciprocity as well as feedback [25]. Therefore, the higher the degree of trust between individuals and team members, the more knowledge they are willing to share. In addition, Zou et al. (2015) found through research that TMX mediates the positive relationship between service leaders and helping behaviors towards colleagues, while individual reciprocal beliefs play a moderating role in service leaders and TMX. That is to say, when individuals' reciprocal belief is high, the positive relationship between service leaders and TMX will be stronger, the positive relationship between service leaders and help-seeking behavior through TMX will be stronger as well. [18].

At the team level, Tse et al. (2008) found that although high-quality LMX relationships produce high-quality TMX relationships for individual, level of LMXD will impact TMX too. The higher the level of LMXD, the lower the quality of individuals TMX relationships will be [21]. It is because the greater the difference in leader-member exchanges perceived by individuals, the stronger the sense of unfairness generated [7], which in turn affects effective communication between team members. Even worse, high level of LMXD improve the tendency of
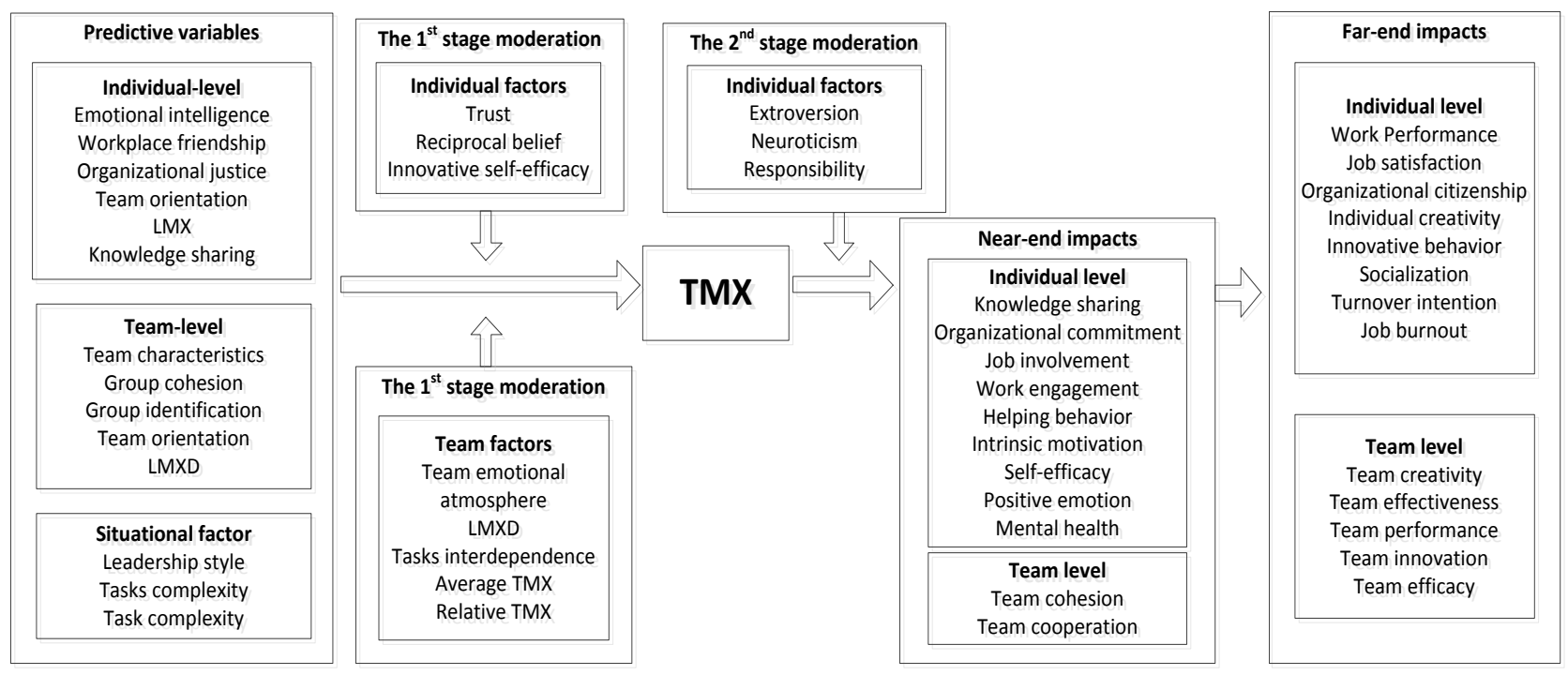

Figure 1. An integrated research framework of TMX. Source: made by the author. 
conflicts. What's more, the research studied by de Jong et al. (2014) shows that the influence of negative relationships between team members on team cohesion can be regulated by task interdependency. The higher the level of task interdependence, the lower the destructive effect of negative relationships on team cohesion [32]. Therefore, similarly, high levels of task interdependence require team members to communicate, share and cooperate more related to tasks, which also help build good quality of TMX relationship. Based on optimal traits (ODT) of social identity theory, Farmer et al. (2015) points out that individuals have both assimilation needs (i.e., the need for collective identity and belonging) and differentiated needs (i.e., individual identity, uniqueness, and distinctiveness) and identification generated after two kinds of needs are met at the same time. The team's high level of relative TMX (the relative TMX relationship with different members) can meet the individual's differentiated needs while the high level of average TMX (the overall TMX relationship quality of the team) can meet the individual assimilation needs. Therefore, the interaction between the average TMX level of the team and the relative TMX level influences the individual's team identity and colleagues' identification, and thus affects the individual's helper behavior [26].

\subsection{The Second Stage Moderation}

The research on the TMX second moderation mechanism is limited. Meta-analysis from Judge and Judge and Ilies (2002) shows that the three personality types in the Big Five personality traits-extroversion, neuroticism, and conscientiousness-are related to motivation output and process (i.e., self-efficacy, expectations, and goal setting) [83]. Liao et al. (2013) assumed that extraversion, neuroticism, and conscientiousness have an impact on the relationship between TMX and job participation. Empirical results show that extraversion is positive to moderate relationship between TMX and job participation. Besides, neuroticism as well as conscientiousness negatively moderate the relationship between TMX and job participation [29].

\section{Future Research Prospects of TMX}

After sorting out TMX research literature, it is not difficult to find that TMXs are inherited in the same vein as leader-member exchanges. However, comparing with system research of leader-member exchange, TMX research is still too fragmented and scarce to form a system. As written above, firstly, there is not enough research on the type of team-member exchange, which leads to the lack of clear structure dimension. In addition, although scholars have explored the antecedents and effects of TMX from angles of individual, team and situational contexts, there are still more factors waiting to be explored. Finally, most moderating mechanism of TMX remains unknown, which in other words means boundary of TMX still unclear. Therefore, there are at least the following two aspects worthy of further study. 


\subsection{Exploration of Team-Level TMX Measurement and TMX Structural Dimension}

In 1989, Seers defined TMX as an individual-level variable, reflecting the individual perception of the quality of the team's work relationship [5]. Most of subsequent research also explored the mechanism of action of TMX from an individual level [13]. Seers, Petty, and Cashman (1995) pointed out that the promotion of TMX to the team level can reflect the quality of the working relationship within the team, which is also of great theoretical significance [14]. However, scholars have not reached an agreement on how to raise individual-level TMX to the team level. For example, some scholars believe that the TMX average can be used to measure team-level TMX. Some scholars believe that the TMX median should be used to represent the team level. Therefore, the definition as well as measurement of team-level TMX plays a critical role on the development of TMX theory. In addition, as described in the structural dimension section above, only the seers (1989) and Tse and Das borough (2008) have explored the dimensions of TMX so far. To clearly explain how the team-level TMX should be defined and measured, future research can be explored on TMX dimensions [14].

\subsection{Exploration of Antecedent and Outcome Factors}

Although many scholars have discussed antecedents as well as results of TMX from different perspectives, there are still many areas worthy of further exploration for the study of causes and consequences of TMX. For example, studies have shown that service leaders influence the quality of the team's TMX. Will other leadership styles such as transactional leaders, transformational leaders, and ethical leaders also affect TMX quality? In addition, as for impact of TMX, most studies only focus on the direct relationship between TMX and individual-level or team-level output [13], failing to clearly reveal its process mechanisms, especially lacking of attention to the interactive process of intra-team cooperation etc. Now it is still difficult to answer the question of how and when TMX influence individual or team. Therefore, in the future, it is also necessary to conduct in-depth discussions on the mechanism. What's more, when it comes to causes of TMX, different scholars have various points. For example, Liu et al. (2011) believe that high-quality TMX relationship not only creates an atmosphere of mutual help and reciprocity, but also provides team members with more opportunities to share and communicate, making the interaction between team members more effective. It is more conducive to individual knowledge sharing [70], while Monica $\mathrm{Hu}$ (2012) holds the points that individual knowledge sharing behavior will enhance his TMX relationship with the team [25]. It can be seen that the relationship between the antecedents as well as outcome variables of TMX is not clear yet, further research should be explored.

\section{Conflicts of Interest}

The authors declare no conflicts of interest regarding the publication of this paper. 


\section{References}

[1] Chae, S., Seo, Y. and Lee, K.C. (2015) Effects of Task Complexity on Individual Creativity through Knowledge Interaction: A Comparison of Temporary and Permanent Teams. Computers in Human Behavior, 42,138-148. https://doi.org/10.1016/j.chb.2013.10.015

[2] George, E., Chattopadhyay, P. and Ng, C.K. (2016) The Relationship between Workgroup Blending and Perceived Organizational Inducements: The Mediating Roles of Tasks and Relationships. Australian Journal of Management, 41, 486-491. https://doi.org/10.1177/0312896215595680

[3] Hoegl, M. and Proserpio, L. (2004) Team Member Proximity and Teamwork in Innovative Projects. Research Policy, 33, 1153-1165. https://doi.org/10.1016/j.respol.2004.06.005

[4] Herdman, A.O., Yang, J. and Arthur, J.B. (2014) How Does Leader-Member Exchange Disparity Affect Teamwork Behavior and Effectiveness in Work Groups: The Moderating Role of Leader-Leader. Exchange Journal of Management, 43, 1498-1523.

[5] Seers, A. (1989) Team-Member Exchange Quality: A New Construct for Role-Making Research. Organizational Behavior \& Human Decision Processes, 43, 118-135. https://doi.org/10.1016/0749-5978(89)90060-5

[6] Brandes, P., Dharwadkar, R. and Wheatley, K. (2004) Social Exchanges within Organizations and Work Outcomes: The Importance of Local and Global Relationships. Group \& Organization Management, 29, 276-301.

https://doi.org/10.1177/1059601103257405

[7] Harris, T.B., Li, N. and Kirkman, B.L. (2014) Leader-Member Exchange in Context: How LMX Differentiation and LMX Relational Separation Attenuate LMX's Influence on OCB and Turnover Intention. Leadership Quarterly, 25, 314-328. https://doi.org/10.1016/j.leaqua.2013.09.001

[8] Volmer, J., Spurk, D. and Niessen, C. (2012) Leader-Member Exchange, Job Autonomy, and Creative Work Involvement. Leadership Quarterly, 23, 456-465. https://doi.org/10.1016/j.leaqua.2011.10.005

[9] Carson, J.B. and Marrone, J.A. (2007) Shared Leadership in Teams: An Investigation of Antecedent Conditions and Performance. Academy of Management Journal, 50, 1217-1234.

[10] Bunderson, J.S. and Boumgarden, P. (2010) Structure and Learning in Self-Managed Teams: Why "Bureaucratic" Teams Can Be Better Learners. Organization Science, 21, 609-624. https://doi.org/10.1287/orsc.1090.0483

[11] Pérez, J.B. and Zárraga, C. (2005) The Impact of Team Atmosphere on Knowledge Outcomes in Self-Managed Teams. Organization Studies, 26, 661-681.

https://doi.org/10.1177/0170840605051820

[12] Dierdorff, E.C., Bell, S.T. and Belohlav, J.A. (2011) The Power of "We": Effects of Psychological Collectivism on Team Performance over Time. Journal of Applied Psychology, 96, 247-262. https://doi.org/10.1037/a0020929

[13] Banks, G.C., et al. (2014) What Does Team-Member Exchange Bring to the Party? A Meta-Analytic Review of Team and Leader Social Exchange. Journal of Organizational Behavior, 35, 273-295. https://doi.org/10.1002/job.1885

[14] Seers, A., Petty, M.M. and Cashman, J.F. (1995) Team-Member Exchange under Team and Traditional Management: A Naturally Occurring Quasi-Experiment. Group \& Organization Management, 20, 18-38. 
https://doi.org/10.1177/1059601195201003

[15] Liden, R.C., Sparrowe, R.T. and Wayne, S.J. (1997) Leader-Member Exchange Theory: The Past and Potential for the Future. Research in Personnel \& Human Resources Management, 15, 47-119.

[16] Love, M.S. and Forret, M. (2008) Exchange Relationships at Work: An Examination of the Relationship between Team-Member Exchange and Supervisor Reports of Organizational Citizenship Behavior. Journal of Leadership \& Organizational Studies, 14, 342-352. https://doi.org/10.1177/1548051808315558

[17] Zhou, W. and Liu, J. (2011) One for All, All for One: Review of Research on Team-Member Exchange. Advances in Psychological Science, 19, 1193-1204.

[18] Zou, W.C., Tian, Q. and Liu, J. (2015) Servant Leadership, Social Exchange Relationships, and Follower's Helping Behavior: Positive Reciprocity Belief Matters. International Journal of Hospitality Management, 51, 147-156. https://doi.org/10.1016/j.ijhm.2015.08.012

[19] Hoegl, M., Praveen Parboteeah, K. and Gemuenden, H.G. (2003) When Teamwork Really Matters: Task Innovativeness as a Moderator of the Teamwork-Performance Relationship in Software Development Projects. Journal of Engineering and Technology Management, 20, 281-302. https://doi.org/10.1016/j.jengtecman.2003.08.001

[20] Tse, H.H.M. and Dasborough, M.T. (2008) A Study of Exchange and Emotions in Team Member Relationships. Group \& Organization Management, 33, 194-215. https://doi.org/10.1177/1059601106293779

[21] Tse, H.H.M., Dasborough, M.T. and Ashkanasy, N.M. (2008) A Multi-Level Analysis of Team Climate and Interpersonal Exchange Relationships at Work. The Leadership Quarterly, 19, 195-211. https://doi.org/10.1016/j.leaqua.2008.01.005

[22] Chiaburu, D.S., Lorinkova, N.M. and Van Dyne, L. (2013) Employees' Social Context and Change-Oriented Citizenship: A Meta-Analysis of Leader, Coworker, and Organizational Influences. Group \& Organization Management, 38, 291-333. https://doi.org/10.1177/1059601113476736

[23] Abu Bakar, H. and Sheer, V.C. (2013) The Mediating Role of Perceived Cooperative Communication in the Relationship between Interpersonal Exchange Relationships and Perceived Group Cohesion. Management Communication Quarterly, 27, 443-465. https://doi.org/10.1177/0893318913492564

[24] Tziner, A. and Vardi, Y. (1982) Effects of Command Style and Group Cohesiveness on the Performance Effectiveness of Self-Selected Tank Crews. Journal of Applied Psychology, 67, 769-775. https://doi.org/10.1037/0021-9010.67.6.769

[25] Monica Hu, M., Ou, T., Chiou, H. and Lin, L. (2012) Effects of Social Exchange and Trust on Knowledge Sharing and Service Innovation. Social Behavior and Personality: An International Journal, 40, 783-800. https://doi.org/10.2224/sbp.2012.40.5.783

[26] Farmer, S.M., Van Dyne, L. and Kamdar, D. (2015) The Contextualized Self: How Team-Member Exchange Leads to Coworker Identification and Helping OCB. Journal of Applied Psychology, 100, 583-595. https://doi.org/10.1037/a0037660

[27] Wang, Z., Li, C., Wu, J. and Liu, L. (2014) The Mediating Effect of Cooperative Goals on the Relationship between Team Orientation and Team Member Exchange. Social Behavior and Personality: An International Journal, 42, 685-693. https://doi.org/10.2224/sbp.2014.42.4.685

[28] Zhang, S., et al. (2014) Relational versus Collective Identification within Workgroups: Conceptualization, Measurement Development, and Nomological Network Building. Journal of Management, 40, 1700-1731. 
https://doi.org/10.1177/0149206312439421

[29] Liao, F.Z., et al. (2013) Team-Member Exchange and Work Engagement: Does Personality Make a Difference? Journal of Business and Psychology, 28, 63-77. https://doi.org/10.1007/s10869-012-9266-5

[30] Lam, T. (2002) Leader-Member Exchange and Team-Member Exchange: The Roles of Moderators in New Employees' Socialization. Journal of Hospitality \& Tourism Research, 27, 48-68. https://doi.org/10.1177/1096348002238880

[31] Sherony, K.M. and Green, S.G. (2002) Coworker Exchange: Relationships between Coworkers, Leader-Member Exchange, and Work Attitudes. Journal of Applied Psychology, 87, 542-548. https://doi.org/10.1037/0021-9010.87.3.542

[32] de Jong, J.P., Curşeu, P.L. and Leenders, R.T.A.J. (2014) When Do Bad Apples Not Spoil the Barrel? Negative Relationships in Teams, Team Performance, and Buffering Mechanisms. Journal of Applied Psychology, 99, 514-522. https://doi.org/10.1037/a0036284

[33] Blau, P.M. (1964) Justice in Social Exchange. Sociological Inquiry, 34, 193-206. https://doi.org/10.1111/j.1475-682X.1964.tb00583.x

[34] Haynie, J.J. (2012) Core-Self Evaluations and Team Performance: The Role of Team-Member Exchange. Small Group Research, 43, 315-329. https://doi.org/10.1177/1046496411428357

[35] O’Connor, M. and Rafferty, M. (2012) Corporate Governance and Innovation. Journal of Financial and Quantitative Analysis, 47, 397-413. https://doi.org/10.1017/S002210901200004X

[36] Loi, R., Mao, Y. and Ngo, H. (2009) Linking Leader-Member Exchange and Employee Work Outcomes: The Mediating Role of Organizational Social and Economic Exchange. Management and Organization Review, 5, 401-422. https://doi.org/10.1111/j.1740-8784.2009.00149.x

[37] Zhang, Y., Wang, X. and Zhang, X. (2015) A Literature Review of Differentiated Transformational Leadership and Prospects. Foreign Economies and Management, 37, 43-53.

[38] Fehr, E. and Kirchsteiger, G. (1997) Reciprocity as a Contract Enforcement Device: Experimental Evidence. Econometrica, 65, 833-860. https://doi.org/10.2307/2171941

[39] Vigoda-Gadot, E. (2007) Redrawing the Boundaries of OCB? An Empirical Examination of Compulsory Extra-Role Behavior in the Workplace. Journal of Business and Psychology, 21, 377-405. https://doi.org/10.1007/s10869-006-9034-5

[40] Biddle, B.J. (1981) Role Theory: Expectations, Identities, and Behaviors. Social Forces, 30, 553-568.

[41] Ii, R.J.U., Bode, M. and Shimizu, K.D. (2012) Integrating Foreign Policy Analysis and International Relations through Role Theory. Foreign Policy Analysis, 8, 1-4.

[42] Broderick, A.J. (1998) Role Theory, Role Management and Service Performance. Journal of Services Marketing, 12, 348-361. https://doi.org/10.1108/08876049810235379

[43] Palmer, B.R., Gignac, G., Manocha, R. and Stough, C. (2012) A Psychometric Evaluation of the Mayer-Salovey-Caruso Emotional Intelligence Test Version 2.0. Intelligence, 33, 285-305. https://doi.org/10.1016/j.intell.2004.11.003

[44] Mayer, J.D., Caruso, D.R., Panter, A.T. and Peter, S. (2012) The Growing Significance of Hot Intelligences. American Psychologist, 67, 502-503.

https://doi.org/10.1037/a0029456 
[45] Brackett, M.A. and Salovey, P. (2006) Measuring Emotional Intelligence with the Mayer-Salovery-Caruso Emotional Intelligence Test (MSCEIT). Psicothema, 18, 34-41.

[46] Mao, H. (2006) The Relationship between Organizational Level and Workplace Friendship. International Journal of Human Resource Management, 17, 1819-1833. https://doi.org/10.1080/09585190600965316

[47] Sias, P.M. and Avdeyeva, G.S.T. (2009) Sex and Sex-Composition Differences and Similarities in Peer Workplace Friendship Development. Communication Studies, 54, 322-340. https://doi.org/10.1080/10510970309363289

[48] Sias, P.M., Pedersen, H., Gallagher, E.B. and Kopaneva, I. (2012) Workplace Friendship in the Electronically Connected Organization. Human Communication Research, 38, 253-79. https://doi.org/10.1111/j.1468-2958.2012.01428.x

[49] Lin, C.T. (2006) Relationship between Job Position, Job Attributes, and Workplace Friendship: Taiwan and China. Journal of Technology Management in China, 5, 55-68.

[50] Greenberg, J. (1990) Organizational Justice: Yesterday, Today, and Tomorrow. Journal of Management, 16, 399-432. https://doi.org/10.1177/014920639001600208

[51] Wesman, E.C. (1992) Organizational Justice: The Search for Fairness in the Workplace. Academy of Management Review, 1, 152-156.

[52] Li, Y. and Long, L. (2003) The Enlightenment of Organizational Justice Research on Human Resource Management. Foreign Economies and Management, 25, 12-17.

[53] Hubbell, A.P. and Assad, R.M.C. (2005) Motivating Factors: Perceptions of Justice and Their Relationship with Managerial and Organizational Trust. Communication Studies, 56, 47-70. https://doi.org/10.1080/0008957042000332241

[54] Bjerknes, M. and Cheng, H. (2014) The Effects of Organizational Justice on Organizational Citizenship Behavior in the Chinese Context the Mediating Effects of Social Exchange Relationship. Public Personnel Management, 43, 301-313. https://doi.org/10.1177/0091026014533897

[55] Mohammed, S. and Angell, L.C. (2004) Surface- and Deep-Level Diversity in Workgroups: Examining the Moderating Effects of Team Orientation and Team Process on Relationship Conflict. Journal of Organizational Behavior, 25, 1015-1039. https://doi.org/10.1002/job.293

[56] Taggar, S. and Ellis, R. (2007) The Role of Leaders in Shaping Formal Team Norms. The Leadership Quarterly, 18, 105-120. https://doi.org/10.1016/j.leaqua.2007.01.002

[57] Hooper, D.T. and Martin, R. (2008) Beyond Personal Leader-Member Exchange Quality: The Effects of Perceived LMX Variability on Employee Reactions. The Leadership Quarterly, 19, 20-30. https://doi.org/10.1016/j.leaqua.2007.12.002

[58] Alge, B.J., Wiethoff, C. and Klein, H.J. (2003) When Does the Medium Matter? Knowledge-Building Experiences and Opportunities in Decision-Making Teams. Organizational Behavior and Human Decision Processes, 91, 26-37. https://doi.org/10.1016/S0749-5978(02)00524-1

[59] Ismail, N.Q.A., Hamzah, M.H., Ngah, K. and Mustaffa, J. (2012) Work Unit Context: The Dyadic, Team Members Relationships and Group Outcomes in a Malaysian Organization. Business Management Dynamics, 1, 22-32.

[60] Gajendran, R.S. and Aparna, J. (2012) Innovation in Globally Distributed Teams: The Role of LMX, Communication Frequency, and Member Influence on Team Decisions. Journal of Applied Psychology, 97, 1252-1261.

https://doi.org/10.1037/a0028958 
[61] Lawler, E.J. and Yoon, J. (2000) Emotion and Group Cohesion in Productive Exchange. American Journal of Sociology, 106, 616-657. https://doi.org/10.1086/318965

[62] Wang, E.T.G., Ying, T.C., Jiang, J.J. and Klein, G. (2006) Group Cohesion in Organizational Innovation: An Empirical Examination of ERP Implementation. Information \& Software Technology, 48, 235-244.

https://doi.org/10.1016/j.infsof.2005.04.006

[63] Marziali, E., Munroe-Blum, H. and Mccleary, L. (1997) The Contribution of Group Cohesion and Group Alliance to the Outcome of Group Psychotherapy. International Journal of Group Psychotherapy, 47, 475-497. https://doi.org/10.1080/00207284.1997.11490846

[64] Yuan, L., Xiao, S., Li, J., Chen, C. and Ning, L. (2016) Leader-Member Exchange Differentiation and Team Member Performance: The Moderating Role of the Perception of Organizational Politics. International Journal of Manpower, 37, 1347-1364. https://doi.org/10.1108/IJM-11-2014-0221

[65] Le Blanc, P.M. and González-Romá, V. (2012) A Team Level Investigation of the Relationship between Leader-Member Exchange Differentiation, and Commitment and Performance. The Leadership Quarterly, 23, 534-544.

https://doi.org/10.1016/j.leaqua.2011.12.006

[66] Kim, S.K. and Radosevich, D.J. (2007) The Impact of Workplace Envy on Organizational Citizenship Behavior with Leader-Member Exchange in the Service Industry. Review of Business Research, 7, 158-167.

[67] Chen, Y., Yu, E. and Son, J. (2014) Beyond Leader-Member Exchange (LMX) Differentiation: An Indigenous Approach to Leader-Member Relationship Differentiation. The Leadership Quarterly, 25, 611-627. https://doi.org/10.1016/j.leaqua.2013.12.004

[68] Walumbwa, F.O., Hartnell, C.A. and Adegoke, O. (2010) Servant Leadership, Procedural Justice Climate, Service Climate, Employee Attitudes, and Organizational Citizenship Behavior: A Cross-Level Investigation. Journal of Applied Psychology, 95, 517-529. https://doi.org/10.1037/a0018867

[69] Hoegl, M. and Gemuenden, H.G. (2001) Teamwork Quality and the Success of Innovative Projects: A Theoretical Concept and Empirical Evidence. Organization Science, 12, 435-449. https://doi.org/10.1287/orsc.12.4.435.10635

[70] Liu, Y., Keller, R.T. and Hsi An, S. (2011) The Impact of Teamcmember Exchange, Differentiation, Team Commitment, and Knowledge Sharing on R\&D Project Team Performance. $R \& D$ Management, 41, 274-287.

[71] Bishop, J.W. and Scott, K.D. (2000) An Examination of Organizational and Team Commitment in a Self-Directed Team Environment. Journal of Applied Psychology, 85, 439-450. https://doi.org/10.1037/0021-9010.85.3.439

[72] Cropanzano, R. and Mitchell, M.S. (2005) Social Exchange Theory: An Interdisciplinary Review. Journal of Management, 31, 874-900.

https://doi.org/10.1177/0149206305279602

[73] Brooke, P.P., Russell, D.W. and Price, J.L. (1988) Discriminant Validation of Measures of Job Satisfaction, Job Involvement, and Organizational Commitment. Journal of Applied Psychology, 73, 139-145. https://doi.org/10.1037/0021-9010.73.2.139

[74] Sabine, S. (2003) Recovery, Work Engagement, and Proactive Behavior: A New Look at the Interface between Nonwork and Work. Journal of Applied Psychology, 88, 518-528. https://doi.org/10.1037/0021-9010.88.3.518

[75] Cogliser, C.C., et al. (2013) Not All Group Exchange Structures Are Created Equal: 
Effects of Forms and Levels of Exchange on Work Outcomes in Virtual Teams. Journal of Leadership \& Organizational Studies, 20, 242-251. https://doi.org/10.1177/1548051812472370

[76] Chen, Z. and Wu, H. (2008) Intrinsic Motivation and Its Antecedents. Advances in Psychological Science, 16, 98-105.

[77] Wann, D.L., Waddill, P.J., Polk, J. and Weaver, S. (2011) The Team Identification-Social Psychological Health Model: Sport Fans Gaining Connections to Others via Sport Team Identification. Group Dynamics Theory Research \& Practice, 15, 75-89. https://doi.org/10.1037/a0020780

[78] Liao, H., Liu, D. and Loi, R. (2010) Looking at Both Sides of the Social Exchange Coin: A Social Cognitive Perspective on the Joint Effects of Relationship Quality and Differentiation on Creativity. Academy of Management Journal, 53, 1090-1109. https://doi.org/10.5465/amj.2010.54533207

[79] Tjosvold, D., Johnson, D.W. and Johnson, R. (1984) Influence Strategy, Perspective-Taking, and Relationships between High- and Low-Power Individuals in Cooperative and Competitive Contexts. Journal of Psychology Interdisciplinary \& Applied, 116, 187-202. https://doi.org/10.1080/00223980.1984.9923636

[80] Sun, R., Shi, J.T. and Zhang, T.Q. (2009) An Empirical Research on Relationship in LMX, TMX, Organization Climate for Innovation and Innovational Behavior in China. Journal of Industrial Engineering \& Engineering Management, 23, 109-115.

[81] Cruz, K.S. and Pil, F.K. (2011) Team Design and Stress: A Multilevel Analysis. Human Relations, 64, 1265-1289. https://doi.org/10.1177/0018726711409264

[82] Liang, R. (2012) The Structural Dimension of Team-Member Exchange and Its Relationship with Organizational Commitment and Job Burnout. Psychological EXploration, 32, 560-563.

[83] Judge, B.T.A. and Ilies, R. (2002) Relations of Personality to Performance Motivation: A Meta Analytic Review. Journal of Applied Psychology, 88, 533-568. 